\title{
Review of the Book "Historical Memory in Social Media" by Sophia Tikhonova, Denis Artamonov
}

\section{Artur A. Dydrov}

South Ural State University (National Research University). Chelyabinsk, Russia.

Email: zenonstoik[at]mail.ru

\section{Abstract}

The subject of review is the book "Historical Memory in Social Media" by Sofya Tikhonova and Denis Artamonov. In the book, the authors focus on the design and specification of the production of images of the past on the Internet and the gaming industry, referring to various materials, from text "fake" messages and memes to computer games. Research is not limited to the description of empirical data. The supporting structure of the research is the author's concept of digital history and digital philosophy of history. Research optics is aimed at determining the status of the digital subject of history, which seems to be an acute anthropological and socio-philosophical problem. The book discusses the issues of modification of the politics of memory, the production of "fakes", the connotation of historical events, the trend of miniaturization of history and the crisis of great narratives. Considerable attention is paid to the everyday everyday practices of information production, woven into the context of "history making". The review pays attention to all the main structural parts of the book and reproduces the logical sequence of the key ideas of the text. With references to the original author's text, the reviewer also gives his own interpretations of the conceptual and terminological innovations of the book, and also focuses on some controversial aspects of the research.

\section{Keywords}

Social Media; Historical Memory; History Hacking; Digital Subject; Fake; Meme; Complex of Memes; Memorial War; Myth; Gamification of History 


\section{Рецензия на книгу «Историческая память в социальных медиа» С. В. Тихоновой, Д. С. Артамонова}

\section{Дыдров Артур Александрович}

Южно-Уральский государственный университет (национальный исследовательский университет). Челябинск, Россия. Email: zenonstoik[at]mail.ru

\section{Аннотация}

Предметом рецензирования выступает монографическое исследование С. В. Тихоновой и Д. С. Артамонова «Историческая память в социальных медиа». В монографии авторы акцентируют внимание на конструировании и спецификации производства образов прошлого в сети «Интернет» и игровой индустрии, обращаясь к различному материалу, от текстовых «фейковых» сообщений и мемов до компьютерных игр. Исследование не сводится при этом к дескрипции эмпирического материала. Несущей конструкцией монографии является авторская концепция цифровой истории и цифровой философии истории. Исследовательская оптика направлена на определение статуса цифрового субъекта истории, что представляется острой философско-антропологической и социально-философской проблемой. В монографии обсуждаются вопросы модификации политики памяти, производства «лжефактов», коннотации исторических событий, тенденция миниатюризации истории и кризиса великих нарративов. Значительное внимание уделено и повседневным обыденным практикам производства информации, вплетённым в контекст «хисторимейкинга». В рецензии уделяется внимание всем основным структурным частям монографии и воспроизводится логическая последовательность ключевых идей текста. Со ссылками на оригинальный авторский текст, рецензент даёт и собственные интерпретации понятийно-терминологических новаций монографии, а также акцентирует внимание на некоторых дискуссионных моментах исследования.

\section{Ключевые слова}

социальные медиа; историческая память; хисторихакинг; цифровой субъект; фейк; мем; комплекс мемов; мемориальная война; миф; геймификация истории 
Образы прошлого так же, как и образы будущего, сравнительно часто оказываются в фокусе внимания исследователей. Не составляют исключение и философы, занимающиеся не только экспликацией или дескрипцией образов, но и концептуализацией разнообразного материала. «Диджитализация» и «интернетизация» профессиональной деятельности человека и вообще повседневной жизни представляются сложнейшими процессами, которые в принципе невозможно зафиксировать средствами какой-либо одной науки. Человек создал новую среду, требующую исключительно междисциплинарного исследования. Несмотря на то, что научные труды о «цифровой эпохе», «цифровизации» и «диджитализации» стремительно возникают едва ли не каждый день, всегда остаются предметы, требующие основательного изучения. Образы прошлого в социальных медиа, бесспорно, являются таким предметом.

Концептуализация видится особенно необходимой в условиях интенсификации информационных процессов, перманентного увеличения объёмов данных, открытого доступа к информации. Последнее вызывает как самые положительные отклики, так и настороженные оценки. С одной стороны, интенсификация информационных потоков является индикатором демократизации общественных отношений, показателем движения и прогресса (в том числе творческого), а с другой стороны, неоднозначно влияет на человека, уподобляя его ницшеанской фигуре мореплавателя, мечтающего пристать к острову.

Прошлое специфическим образом попадает в информационные потоки и об(пере)рабатывается в «новую историю», или историю «по-новому». Монографическое исследование С. В. Тихоновой и Д. С. Артамонова в определённом смысле уникально. В нем читатель может увидеть не только дескрипцию способов корректировки истории и даже «историотворчества», но и концептуализацию этих сложных, многоплановых процессов. Немаловажен и тот факт, что в качестве материала для исследования выступали актуальные формы репрезентации прошлого, перечисленные как в аннотации, так и в основном содержании монографического труда. Эти разнообразные формы авторы назвали «цифровыми формами объективации» (Тихонова, 2021, с. 7). Уникальность «ситуации современности» заключается в том, что человек получил возможность делиться воспоминаниями с неопределённым кругом лиц, минуя всевозможные социальные барьеры.

Монография состоит из четырёх глав, образующих стройное логическое целое: первая глава посвящена методологическому инструментарию изучения образов прошлого и теоретическим основаниям изучения конструирования исторической памяти; во второй главе представлена аналитика «историзации» развлекательного контента (здесь на авансцену выходят мемы, фейки, селфи и др. формы репрезентации); третья глава повествует о «хисторихакинге» (термин авторов), благодатной почвой для которого является разработка компьютерных игр; наконец, в четвертой главе говорится о формировании цифровой истории и даже цифровой философии истории. 
Цифровая среда включает в себя своеобразные «платформы» для производства исторического знания, которые были оригинально названы «эпистемическими аренами» (Тихонова, 2021, с. 28). Корректно дискутируя с М. Кастельсом, авторы подчеркнули, что сетевые структуры (или ризоматическая аструктурность) не вытеснили иерархии, но основательно размягчили их «древесину» (Тихонова, 2021, с. 14). Не ставя цель анализировать новую реальность на макроуровне, С. В. Тихонова и Д. С. Артамонов утверждают, что спецификацию цифрового мира можно выявить средствами микроанализа и, тем самым, обратиться к практикам обывателя (Тихонова, 2021, с. 14). Он - «винтик» smartmob - может рассказать куда больше, нежели космические снимки политологического, социологического и других подходов. В противовес устоявшимся представлениям о толпе, неизменно связывающейся в сознании многих интеллектуалов с хаосом и буйством иррациональности, авторы приводят пример «экспертной толпы», или «вики-толпы» (Тихонова, 2021, с. 18). Иной взгляд авторов монографического исследования на феномен толпы является оригинальным и, более того, необходимым, так как описать новые формы организации в цифровом мире старыми категориями не представляется возможным (по крайней мере, адекватно). Сегодняшние массы прямо или косвенно участвуют в выработке и фиксации исторического знания. Очевидно, что это не только профессиональные сообщества, но и рядовые пользователи.

В дигитальной среде историческая память «разворачивается», по выражению авторов, в ином формате, - как «цифровое прошлое» (Тихонова, 2021, c. 52). При первом приближении можно было бы говорить о том, что изменился только носитель памяти, и место пыльных библиотек и каталогов заняли домены и сайты. Однако, памятуя об авторской метафоре размягченного древа (с вероятной аллюзией к метафорике Делеза - Гваттари (Делез, 2008)), с предыдущим трудно согласиться. Внешне «безобидная» замена носителя решительным образом воздействует на политику памяти и колеблет власть «сакральных» структур, основными функциями которых неопределённо долгое время были хранение и воспроизводство знания о прошлом. Цифровые технологии, обеспечившие возможность полилога и поместившие нас в ситуацию постоянного полидискурсивного «шума», «раскрепостили» человека. Стоит ли говорить о том, что цензура, «полиция знака», вошла в состояние кризиса?

Медиапамять существует в различных форматах, и текст, некогда монополизировавший историческую память, является только одним из них. В Интернет-среде информация оседает, образуя своеобразные слои. По меткому выражению авторов, мусор - это «завтрашний культурный слой, который вчера был востребованным артефактом» (Тихонова, 2021, с. 64). При изменении аксиологической оптики окажется, что любые «заброшенные» данные еще могут оказаться востребованными. Ту или иную однозначную оценку информации вообе удобно давать на субъективно-личностном 
уровне, и обыденное сознание эти оценки активно раздаёт. Но в то время как пользователь копирует, тиражирует, воспроизводит, репродуцирует и т. д., образуется новый культурный слой, который попадёт, рано или поздно, в поле зрения цифровых археологов.

Солидная часть содержания монографии развёртывается в дескрипции форм цифровизации и виртуализации прошлого. Однако, это не означает, что авторы решили избавить себя от труда концептуализации. Каждое вводимое в оборот понятие, каждый новый термин бережно раскрываются и становятся фундаментными блоками в строящемся научном здании. На первый взгляд, некоторые формы цифровизированной «истории» вообще не имеют никакого отношения к «реальному» прошлому. Сюда можно отнести, например, т. н. «исторический» fake. Книжная культура знала примеры «фейкоделания» в лице Фоменко-Носовского, Мулдашева, Бушкова, Немоляева-Семашко и др. Естественно, «фейки» стали и неотъемлемой частью цифровой повседневности. В виртуальном пространстве лжефакты приобрели широкий размах и, что принципиально отличает их от книжных «собратьев», визуализацию. Естественно, зачастую «фейки» сенсационны - так они сильнее отпечатываются в сознании доверчивого и падкого на громкие новости потребителя. К «фейкам» можно отнести страницы вымышленных личностей (равно как и вымышленные профили известных личностей), создание особых документов, мимикрирующих под документы прошлого, новости, фильмы, а также открытие нового исторического источника (когда я пишу эти слова, хочется их закавычить, от «открытия» до «источника»).

Заслуженное место в монографическом исследовании заняли Интернетмемы. Нельзя не согласиться с утверждением, что «мемы и группы мемов (мемокомплексы) могут изменять восприятие локальных или глобальных событий, а иногда полностью «взрывать» устоявшуюся картину социальной реальности» - сегодня это истина, с которой приходится считаться. Важнейшее правило функционирования (а также популярности) мемов заключается в «захватывании» и «переработке» важнейших (или, по-болотовски, «замечательных») событий, старательно перемолотых мифологизирующей машиной культуры. В результате работы такой машины возникает «мифоинформация», конституируемая, по замечанию авторов, отдельными мифами и целыми мифологемами (Тихонова, 2021, с. 100). Мемы упрощают информацию (и это далеко не единственная их функция), выхватывают «яркое» и «пёстрое», преобразуя факты (то есть интерпретации прошлого) и нагружая их дополнительными коннотациями. Концептуальная находка исследователей заключается во введении в оборот понятия «мемориальной войны» - противостояния идеологий и мифологий с неизменным участием продуктов мем-культуры (Тихонова, 2021, сс. 10, 43, 62).

Если дескрипция «фейков» и мемов в качестве форм трансляции (лже)исторического знания и (лже)исторической памяти, в общем, была ожидаемой, то дескрипция селфи не могла не вызвать удивления. Причиной тому 
являются, по-видимому, укоренившиеся представления о правильности и даже естественности монументалистского подхода к истории. Какую ценную информацию могут в таком случае дать селфи? До ознакомления с монографией этот вопрос казался едва ли не риторическим. Однако, ссылаясь на Д. В. Вольф, авторы подчёркивают, что в селфи сопрягаются хроникальный и коммеморативный уровни «мемориального потенциала» (Тихонова, 2021, с. 118). На первом уровне селфи суть личная летопись, перформативное высказывание в фотографии («это есть я»), а на втором - воспроизведение культурной памяти через «актуализацию прошлого в “местах памяти"» («это есть я, а на фоне - «Х»; «Это я рядом с...» и т. д.). Авторы убедительно доказывают, что селфи куда более «разговорчивы», нежели о них принято думать. Они могут многое сообщить и о памятных местах, и о самом «я», навязчиво фигурирующем в кадре, - о его привычках, вкусах, поступках, темпераменте, характере.

Когда И. Хейзинга (Хейзинга, 2007) и О. Финк (Финк, 2017) писали об игре (и в их дискурсах она становилась Игрой), они вряд ли подозревали о том, что возникнет индустрия игр, или игропромышленность. Игра уже сравнительно давно превратилась в коммерческий продукт, удивляющий потребителей своей оригинальностью, новизной, изощрённостью механик, графикой, сюжетными поворотами, разнообразием тем и т. д. По вполне понятным причинам игра имеет особое, уникальное значение в жизни исторической памяти. Подобно кинематографу, игра в союзе с продвинутыми техническими средствами, «обеспечивает ощущение достоверности происходящего в игре на уровне чувственности, активизируя деятельность органов чувств» (Тихонова, 2021, с. 133). Каким образом игра становится (или рождается) носителем исторического? По сути, авторы отвечают на это коротко и ясно:

\section{«... восприятия и их комплексы не могут превратиться в "мир" без смыслового и событийного контекста. Действия в условиях мультимедийной среды станут действиями в условиях другого мира только при наличии определённых законо- мерностей, играющих ограничительную роль для поступков игрока, а также цели и средств ее достижения. Мир должен быть упорядочен "до" вхождения в него пользователя, благодаря чему к нему можно будет адаптироваться, изучать его и покорять» (Тихонова, 2021, с. 133).}

Контексты, или «миры» игр разнообразны, и это не только мифические пустоши орков или эльфийские леса. Поля танковых сражений, морские дали с армадами, противостояние вражеских сил, образы исторических личностей и т. д. все чаще возникают в игровой среде. На концептуальном уровне этот процесс можно назвать «геймификацией истории», то есть репрезентацией прошлого в компьютерной игре. Репрезентация истории является не только делом организованных в корпорацию профессионалов и гигантов индустрии. Все чаще, по замечанию авторов, за дело берутся «рядовые», или независимые пользователи («инди»), убеждённые в наличии собственного креативного потенциала. Они самостоятельно используют цифровые технологии 
для создания компьютерных игр на историческую тематику. Этот феномен «низового» креатива и отчасти сегмент DIY-культуры, авторы назвали «хисторихакингом» (Тихонова, 2021, сс. 129-130). Терминологическая новация, по признанию С.В. Тихоновой и Д.С. Артамонова, нуждается в дескрипции. В дескрипции нуждается и само явление, зафиксированное новым термином. Де-факто «инди»-разработчики могут удовлетворять социальный заказ, игнорируя при этом устоявшуюся интерпретацию фактов. Кроме того, историческое в игре часто подчинено стратегическому, а не наоборот. Игра - это мир, в котором игрок выступает внешней вмешивающейся силой. Несмотря на то, что и внешней силе приходится быть в определённых рамках, следовать логике развития «мира» (за границу игровой вселенной можно выйти, выключив ПК), она способна влиять на ситуации. В рецензии я не буду воспроизводить примеры игр и стратегических решений, однако оговорюсь, что недостатка в них в монографии нет. По замечанию исследователей,

«правила игры выступают диктующей тотальностью, определяющей поведение игроков, предписывая им поступки, невозможные в офлайне, заставляя адаптировать к логике их совершения и собственную телесность, и мысли» (Тихонова, 2021, cc. 164-165).

Это утверждение представляется дискуссионным, и может быть справедливым в зависимости от исследовательской оптики. Справедливость данного суждения прямо зависит от того, что мы выводим на авансцену. Определённо, у игры есть правила, и игрок не способен перейти границы допустимого в игровой вселенной. Однако, в границах вселенной субъект не обязан следовать событийной логике игрового мира и может отступать от неё. Это, вероятно, и есть тот «минимум выбора», который сохраняется даже в ситуации самой жёсткой регламентации (согласно старинному анекдоту, у любого солдата есть выбор - он может есть, а может не есть).

Особый интерес представляет заключительная глава монографии, посвящённая применению цифровых методов и информационных технологий в исторических исследованиях, цифровой философии истории и парадигмальному сдвигу в исторических исследованиях. В ней фактически осуществлено обобщение эмпирического материала (напомню, что обобщения и новаторская терминология есть во всех частях монографии). Концептуализация выводит уже предварительно обобщённую эмпирику на новый уровень - уровень философии истории, настоящего и будущего исторического знания и исторической памяти. Компьютерные технологии произвели к революционным сдвигам в науке и не только в ней. Наука, вдохновлённая синергетическим подходом, вышла на новый уровень междисциплинарности. Учёные (в том числе, историки) были снабжены новым инструментарием. По справедливому замечанию авторов, «цифровая среда, где происходит поиск информации и производство знания, предоставляет не только удобные инструменты познания, но и накладывает отпечаток на само знание, которое становится цифровым и отражает 
цифровую современность» (Тихонова, 2021, с. 190). Объектом новой, цифровой истории, должно стать цифровое общество, применение информационных компьютерных технологий, их влияние на человека и общество.

В ситуации Постмодерна «великие нарративы» (Лиотар, 1998) пошатнулись, а их место заняли микроистории. Место «замечательных» событий заняла повседневность, рутинное. «Монументальная» история существенно потеряла в размерах. Собственно, миниатюризация как будто становится или уже стала тотальным трендом. Миниатюризируется все - чипы и платы, тенденции (Пенн, 2009), инновации. Миниатюризировалась и история, в которой уже фактически нет нарратива. Цифровая философия истории философия ближайшего будущего - бросит все силы на осмысление цифрового общества, цифрового развития и цифрового субъекта.

Исследование вплотную подводит читателя к проблематике статуса цифрового субъекта истории. Гуманитарные науки, как представляется, могут внести в решение обозначенной проблемы трудно оценимый вклад. Представленная к рецензированию монография служит системообразующим началом, кодексом базисных положений цифровой философии истории и философии цифровой истории. Исследование не беспочвенно и опирается на разнообразные идеи учёных-гуманитариев (перечни фамилий и научных трудов можно найти в конце каждой главы), сохраняя при этом «заряд» новизны, выражая творческий подход авторов и включая в себя оригинальные понятийно-терминологические новации. По моему мнению, историкам, социологам, философам, культурологам и др. специалистам необходимо ознакомиться с содержанием этой книги. Эта книга посвящена истории и исторической памяти, однако говорит о настоящем и будущем куда больше, чем некоторые футурологические труды.

\section{Список литературы}

Делёз, Ж. (2008). Капитализм и иизофрения. Екатеринбург: У-Фактория.

Лиотар, Ж. (1998). Состояние постмодерна. Санкт-Петербург: Алетейя.

Пенн, М. (2009). Микротендениии. Маленькие изменения, приводящие к большим переменал. Москва: АСТ.

Тихонова, С. В., \& Артамонов, Д. С. (2021). Историческая память в социальных медиа. Санкт-Петербург: Алетейя.

Финк, Е. (2017). Основные феномены человеческого бытия (А. Гараджа, Пер.). Москва: Канон ${ }^{+}$ РООИ «Реабилитация». Извлечено от http://www.lib.ru/FILOSOF/FINK/fenomeny.txt

Хёйзинга, Й. (2007). Ното ludens. Человек играющий. Санкт-Петербург: Азбука-классика. 


\section{References}

Deleuze, J. (2008). Capitalism and Schizophrenia. Yekaterinburg: U-Factoria. (In Russian).

Fink, E. (2017). Basic Phenomena of Human Being (A. Garadja, Trans.). Moscow: Kanon+ ROUI Rehabilitation. Retrieved from http://www.lib.ru/FILOSOF/FINK/fenomeny.txt (In Russian).

Huizinga, J. (2007). Homo Ludens. St. Petersburg: Azbuka-klassika. (In Russian).

Lyotard, J. (1998). The State of the Postmodern. St. Petersburg: Aletheia. (In Russian).

Penn, M. (2009). Microtrends. Small changes that lead to big changes. Moscow: AST. (In Russian).

Tikhonova, S. V., \& Artamonov, D. S. (2021). Historical Memory in Social Media. St. Petersburg: Aletheia. (In Russian). 